The Government clearly means business, but how many more thousands of deaths - and tens of thousands of injuriesmust occur unnecessarily before a White Paper is published, new legislation is drafted, and time is found for it in the Parliamentary timetable? We hope that doctors who see the havoc caused by drunk drivers will make their views known both on the content and on the urgency of legislation.

${ }^{1}$ Department of Transport. Consultative document on drinking and driving. London: Department of Transport, 1979.

2 Department of the Environment. Drinking and driving. Report of the departmental committee. (Blennerhassett Report.) London: HMSO, 1976.

${ }^{3}$ Department of the Environment. Drinking and driving in Northern Ireland. Belfast: Department of the Environment, 1979.

4 Wright BM. Breath, alcohol, and the law. Br Med f 1977;i:1216-7.

5 Havard JDJ. Alcohol and the driver. Br Med f 1978; ; :1595-7.

6 Sabey BE. A review of drinking and drug-taking in road accidents in Great Britain. TRRL Supplementary Report 441. Crowthorne: Transport and Road Research Laboratory, 1978.

${ }^{7}$ Anonymous. Drinking and driving accidents-does education help? Br Med F 1978;ii:1352-4.

\section{Perioral dermatitis}

The fact that strong topical steroids can change trivial dermatoses of the face into a recognisable entity, perioral dermatitis; has been known since $1972 .^{12}$ The eruption is a persistent erythema composed of papules and papulopustules which extends around the mouth, sparing a narrow zone close to the vermilion border of the lips. In severe examples the cheeks, eyelids, and glabella (the region between the eyebrows) may be affected. Treatment is not easy, since any attempt to discontinue the topical steroid or substitute one of lower potency results in a rebound exacerbation of the eruption. This tempts the patient to resume applications of the strong steroid to obtain relief and so continues the vicious circle.

Wilkinson et $a l^{3}$ have recently reviewed 203 patients seen in the last 12 years, confirming the findings of others that perioral dermatitis is predominantly a disorder of young women. ${ }^{14}$ Of their 203 patients, 173 were women, 15 were men, and 15 children under 12 . The average age of patients with rosacea, with which perioral dermatitis may be confused, is considerably older. Wilkinson et $a l^{3}$ tested some of the theories that have been put forward to explain the disorder, but they found no pathogenic organisms or Demodex folliculorum; patch tests showed no evidence of contact sensitivity to cosmetics; and hormonal factors, including the use of oral contraceptives, showed no correlation with the eruption. Another recent theory, ${ }^{5}$ that fluorinated toothpaste might be the cause, was excluded, since patients recovered while still using it. The final conclusion-as might be expected-was that, since all but nine patients had admitted the use of topical corticosteroids, misuse of these preparations offered the most satisfactory explanation for the onset of the eruption. Further support for this theory comes from the rise in the number of cases of perioral dermatitis in 1966-70, when corticosteroids were used extensively on the face, and the fall as the knowledge of their possible aetiological role spread at first to the medical profession and later, via the press, to the public.

Yet, despite all the publicity, Cotterill saw 43 patients with perioral dermatitis between 1974 and $1978 .^{\circ}$ All his patients had used topical steroid preparations on the face, but 15 of them had obtained the drugs without consulting a doctor. The usual source of supply was a tube of ointment prescribed for another member of the family. Cotterill made another important point. Seven patients had used hydrocortisone butyrate, a non-fluorinated steroid, which does not interfere with the beneficial effect of tetracycline in perioral dermatitis. ${ }^{7}$ $\mathrm{He}$ listed other relatively weak steroids, including clobetasol butyrate, which he also blamed.

The conclusion must be that any steroid preparation stronger than $1 \%$ hydrocortisone may cause perioral dermatitis when applied to the face. Since self-medication is so common, Cotterill has suggested that tubes of steroid cream should carry a warning notice about their use on the face, and this proposal deserves serious attention from the manufacturers. Once diagnosed, the treatment of perioral dermatitis is simple. Almost always the condition can be resolved by a course of oral oxytetracycline $250 \mathrm{mg}$ twice daily at least 45 minutes before a meal for four weeks, followed by another month's treatment with one tablet daily, and the withdrawal of all topical steroids as soon as possible. Patients should be warned that an uncomfortable flare-up is to be expected but that this usually subsides in two weeks. One final comment: powerful topical steroids are sometimes indicated in the treatment of some skin disorders of the face; but well-informed patients may question this form of treatment, and their doubts warrant a detailed explanation.

Sneddon I. Perioral dermatitis. Br $\mathcal{f}$ Dermatol $1972 ; 87: 430-4$.

2 Weber G. Rosacea-like dermatitis: contraindication or intolerance reaction to strong steroids. Br f Dermatol $1972 ; 86: 253-9$.

3 Wilkinson DS, Kirton V, Wilkinson JD. Perioral dermatitis: a 12-year review. Br F Dermatol 1979;101:245-57.

${ }^{4}$ Hjorth N, Osmundsen P, Rook AJ, Wilkinson DS, Marks R. Perioral dermatitis. Br F Dermatol 1968;80:307-13.

${ }^{5}$ Melletle JR, Aeling JL, Nuss DD. Fluoride tooth paste: a cause of perioral dermatitis. Arch Dermatol 1976;112:730-1.

${ }^{6}$ Cotterill JA. Perioral dermatitis. Br f Dermatol 1979;101:259-62.

7 Sneddon I. A trial of hydrocortisone butyrate in the treatment of rosacea and perioral dermatitis. Br $\mathcal{F}$ Dermatol 1973;89:505-8.

\section{The uneasy oesophagus}

"Your chest pain is due to cramp in the gullet," says the physician out to reassure his worried patient who believes that he has heart disease. How often, however, do symptoms really originate in the oesophageal muscle? Barium swallow radiographs can certainly show non-propulsive ("tertiary") contractions in many people on occasions. These are highpressure squeezes which are not co-ordinated as part of a progressive peristaltic wave; they become more common with advancing years, and the condition has been called presbyoesophagus. The normal motility of the oesophagus may eventually become disorganised, with diminished peristalsis and dilatation of the lumen; the cause is thought to be muscular atrophy rather than autonomic neuropathy. ${ }^{1}$

The difficulty of classifying disorders of oesophageal motility stems from the considerable overlap in signs and symptoms-and, to complicate matters further, spasm may occur with any lesion causing oesophageal obstruction or oesophagitis. The best-known neuromuscular motor disorder is achalasia of the cardia. ${ }^{2}$ Damage to the myenteric plexus of the entire oesophagus causes loss of the normal peristaltic wave and failure of the lower oesophageal sphincter to relax. Away from South America-where the picture is complicated by a type of achalasia due to Chagas's disease-the annual incidence is about 1 in $100000 .{ }^{4}$ Dysphagia is the cardinal symptom, but the clinical picture is eventually completed by the effects of progressive dilatation of the oesophagus with 
retention of its contents. Treatment is directed to the lower oesophageal sphincter and not at the body of the oesophagus. The sphincter may be disrupted by forceful dilatation or incised by a Heller's cardiomyotomy; most authorities favour the surgical approach. ${ }^{5}$

Diffuse spasm of the oesophageal muscle is thought to be even less common, with an incidence of about one-fifth that of achalasia. ${ }^{6}$ Epidemiological data are, however, scanty, and the true incidence may be very much greater. ${ }^{7}$ Asymptomatic persons may nevertheless show typical radiographic and manometric changes, with intermittent localised non-progressive contractions. Manometry shows non-sequential, frequently repeated pressure waves of high amplitude and long duration. In contrast with achalasia, these findings are usually restricted to the distal oesophagus, and the lower oesophageal sphincter is often normal. The sphincter may, however, be affected in one-third of patients, and a few may present a similar clinical picture even though the disorder is confined to a hypertensive or hyperacting lower oesophageal sphincter. ${ }^{8}$ Apart from muscular hypertrophy no characteristic pathological changes are found in the oesophagus in diffuse spasm.

The cardinal symptoms of diffuse spasm are chest pain and dysphagia. They are not only intermittent but they vary in frequency and severity and do not necessarily worsen with time. Symptoms tend to occur in tense, nervous people and are often precipitated by emotional stress. The pain is not necessarily related to eating or drinking and may even occur at night. Manometric studies have shown that pain correlates with the length of a contraction rather than its height. Food rarely becomes impacted; if this happens the diagnosis should be reconsidered and an organic stricture looked for. Again, in contrast to achalasia the lumen is empty, and neither spillover into the lungs nor oesophageal carcinoma occurs as a complication. Medical treatment is usually ineffective, and patients can be advised only to eat slowly, chew food into small boluses, and avoid cold or fizzy drinks. Forceful dilatation is less successful than in achalasia and is probably best avoided. Surgical treatment should be reserved for severe cases; the short-term results of long oesophagomyotomy are favourable, ${ }^{9}$ but we lack information from long-term follow-up, and surgery is probably of less benefit than in achalasia.

In spite of these differences between diffuse spasm and achalasia, there are certain similarities. There is no sex difference in either disease and both occur in adults of any age, though diffuse spasm is more common in older patients. Some patients with achalasia complain of chest pain and show manometric features of both disorders. In the United States of America the syndrome is called "vigorous achalasia," and some British authorities regard it as the early stage of the disease, ${ }^{11}$ though it is probably no more than one end of the clinical range of achalasia. ${ }^{3}$ Nevertheless, there may be a transition from diffuse spasm to achalasia. ${ }^{12}$ Further evidence that these two disorders may share a common aetiology is provided by a recent report of two siblings, one of whom had diffuse spasm and the other achalasia. ${ }^{13}$ Clearly we have much to learn about oesophageal dysmotility.

1 Atkinson, M. Oesophageal motor changes in systemic disease. Clin Gastroenterol 1976:5:119-33.

2 Anonymous. Achalasia of the cardia. Br Med $\mathcal{F} 1974$;ii :515-6.

${ }^{3}$ Harley HRS. Achalasia of the Cardia. Bristol: Wright, 1978.

${ }^{4}$ Earlam RJ, Ellis FH, Nobrega FT, Proceedings of the Mayo Clinic, $1969 ; 44: 478-83$.

5 Ellis FH. Management of oesophageal achalasia. Clin Gastroenterol $1976 ; 5: 89-102$.

${ }^{6}$ Craddock DR, Logan A, Walbaum PR. Diffuse oesophageal spasm. Thorax $1966 ; 21: 511-7$.

${ }^{7}$ Fleshler, B. Diffuse oesophageal spasm. Gastroenterology 1967;52:559-64.
8 Vantrappen G, Hellemans J. Diffuse muscular spasm of the oesophagus and the hypertensive lower oesophageal sphincter. Clin Gastroenterol $1976 ; 5: 59-72$.

9 Gillies M, Nicks R, Skyring A, Clinical, manometric, and pathological studies in diffuse oesophageal spasm. Br Med $\mathcal{F} 1967$;ii :527-30.

${ }^{10}$ Sanderson DR, Ellis Jr FH, Schlegel JF, Olsen AM. Syndrome of vigorous achalasia: clinical and physiologic observations. Diseases of the Chest 1967;52:508-17.

11 Adams CWM, Brain RHF, Ellis FG, Kauntze R, Trounce JR. Achalasia of the cardia. Guy's Hospital Reports, 1961 ;110:191-236.

12 Kramer P, Harris LD, Donaldson RM. Transition from symptomatic diffuse spasm to cardiospasm. Gut $1967 ; 8: 115-9$.

13 Kaye MD, Demeules JE, Achalasia and diffuse oesophageal spasm in siblings. Gut 1979;20:811-4.

\section{Blows from the winter wind}

A so-called "comfort index"1 relates not to the activities of the festive season but to the weather affecting towns throughout the United States. Mortality from ischaemic heart disease was found to be associated with the comfort index but not with socioeconomic factors. In British towns West and Lowe ${ }^{2}$ have shown that mortality from ischaemic heart disease is associated with socioeconomic conditions as well as temperature and rainfall; the effects of the three factors are independent of each other, and temperature is the most highly correlated with mortality. The gradients from south-east to north-west in Britain are from low to high mortality from ischaemic heart disease, from warm to cool and dry to wet weather, and from high to low socioeconomic standards.

Yet seasonal variations in temperature throughout Britain far exceed variations among towns. Last winter the freeze in the first week of the New Year affected the whole of the country. There were about $10 \%$ more deaths registered in the next week than the average for the five weeks after Christmas, and the whole cold spell produced about $10 \%$ more deaths than in the corresponding period of the previous winter. Mortality in the north-west was higher than in the south-east, but the freeze was associated with no greater relative increase in the north than in the south.

The effect of cold is greatest in the elderly; even without severe freezing weather there seems always to be an increase in mortality from ischaemic heart disease in those aged over 65 , and even more in those over 75 , shortly after the winter drop in temperature. ${ }^{3}$ This susceptibility to cold is enhanced by polluted air or respiratory infections. Air pollution is now less severe than in the past. The Clean Air Act was drawn up after the 1952 London smog, which was blamed for 4000 excess deaths. The lesser smog in December 1962 produced about 500 excess deaths in London. But despite the "deadly cold," 4 which continued through January 1963-cases of frostbite being admitted to London hospitals ${ }^{5}$ - there were fewer deaths in that month than in the corresponding period the previous year, ${ }^{6}$ probably because influenza was less prevalent.

If winter comes, can spring be far behind? While we all look forward to the spring and then to the summer, the heat waves of June 1968, August 1975, and June-July 1976 caused, at their peak, as many deaths in one day as the peak of the corresponding winters; this lethal effect was apparent for only about one day in 1966, but for several weeks in 1975 and $1976 .{ }^{7}$

We cannot alter the climate, and doctors have little influence on the socioeconomic environment of less privileged areas 